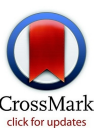

Department of Epidemiology,

Harvard School of Public Health,

Boston MA, USA

${ }^{2}$ Department of Environmental

Health, Harvard School of Public Health, Boston MA, USA

${ }^{3}$ Department of Epidemiology, Johns Hopkins Bloomberg

School of Public Health,

Baltimore MD, USA

${ }^{4}$ Channing Division of Network Medicine, Department of

Medicine at Brigham and

Women's Hospital and Harvard

Medical School, Boston MA

USA

${ }^{5}$ Department of Psychiatry,

Brigham and Women's Hospital and Harvard Medical School,

Boston MA, USA

Correspondence to: M C Power Johns Hopkins University,

Phipps 446D, 600 North Wolfe

Street, Baltimore, MD 21287,

USA melindacpower@gmail.

com

Additional material is published online only. To view please visit the journal online (http:// dx.doi.org/10.1136/BMJ.h1111)

Cite this as: BMJ 2015;350:h1111 doi:10.1136/bmj.h1111

Accepted: 5 February 2015
OPEN ACCESS

\section{The relation between past exposure to fine particulate air pollution and prevalent anxiety: observational cohort study}

\author{
Melinda C Power, 1, 2,3 Marianthi-Anna Kioumourtzoglou, ${ }^{2}$ Jaime E Hart, 2, 4 Olivia I Okereke,, 4,5 \\ Francine Laden,1, 2,4 Marc G Weisskopf1, 2
}

\begin{abstract}
OBJECTIVE

To determine whether higher past exposure to particulate air pollution is associated with prevalent high symptoms of anxiety.

DESIGN

Observational cohort study.

SETTING

Nurses' Health Study.

PARTICIPANTS

71271 women enrolled in the Nurses' Health Study residing throughout the contiguous United States who had valid estimates on exposure to particulate matter for at least one exposure period of interest and data on anxiety symptoms.
\end{abstract}

\section{MAIN OUTCOME MEASURES}

Meaningfully high symptoms of anxiety, defined as a score of 6 points or greater on the phobic anxiety subscale of the Crown-Crisp index, administered in 2004.

\section{RESULTS}

The 71271 eligible women were aged between 57 and 85 years (mean 70 years) at the time of assessment of anxiety symptoms, with a prevalence of high anxiety symptoms of $15 \%$. Exposure to particulate matter was characterized using estimated average exposure to particulate matter $<2.5 \mu \mathrm{m}$ in diameter $\left(\mathrm{PM}_{2.5}\right)$ and 2.5 to $10 \mu \mathrm{m}$ in diameter $\left(\mathrm{PM}_{2.5-10}\right)$ in the one month, three months, six months, one year, and 15 years prior to assessment of anxiety symptoms, and residential distance to the nearest major road two years prior to assessment. Significantly increased odds of high anxiety symptoms were observed with higher exposure to $\mathrm{PM}_{2.5}$ for multiple averaging periods (for example, odds ratio per $10 \mu \mathrm{g} / \mathrm{m}^{3}$ increase in prior one month average $\mathrm{PM}_{2.5}: 1.12,95 \%$ confidence interval 1.06 to 1.19 ; in prior 12 month average $\mathrm{PM}_{2.5}: 1.15,1.06$ to 1.26 ). Models including multiple exposure windows suggested short term averaging periods were more

\section{WHAT IS ALREADY KNOWN ON THIS TOPIC}

Toxicological work suggests exposure to particulate air pollution may induce or exacerbate anxiety through increased oxidative stress and systemic inflammation

While a small but growing body of literature suggests an association between air pollution and mental health outcomes, including anxiety, data on the relation between exposure to particulate air pollution and anxiety in humans is lacking

\section{WHAT THIS STUDY ADDS}

Our study suggests that higher exposure to $\mathrm{PM}_{2.5}$ (particulate matter $<2.5 \mu \mathrm{m}$ in diameter) especially higher recent exposure, is associated with an increased risk of high symptoms of anxiety relevant than long term averaging periods. There was no association between anxiety and exposure to $\mathrm{PM}_{2.5-10}$. Residential proximity to major roads was not related to anxiety symptoms in a dose dependent manner.

\section{CONCLUSIONS}

Exposure to fine particulate matter $\left(\mathrm{PM}_{2.5}\right)$ was associated with high symptoms of anxiety, with more recent exposures potentially more relevant than more distant exposures. Research evaluating whether reductions in exposure to ambient $\mathrm{PM}_{2.5}$ would reduce the population level burden of clinically relevant symptoms of anxiety is warranted.

\section{Introduction}

Anxiety disorders, characterized by disruptive fear, worry, and related behavioral disturbances such as avoidance or physical sensations of hyperarousal, ${ }^{1}$ are the most common type of psychiatric disorder in the general population. ${ }^{2}$ Globally, approximately $16 \%$ of people will have an anxiety disorder in their lifetime and $11 \%$ will have experienced an anxiety disorder in the past year. ${ }^{2}$ Anxiety disorders are associated with reduced productivity and increased psychiatric and non-psychiatric medical care, absenteeism, and risk of suicide. $^{3}$ In 2010, anxiety disorders accounted for approximately 26.8 million disability adjusted life years worldwide. ${ }^{4}$ The monetary cost of anxiety disorders is also substantial; in the United States, the annual direct cost of anxiety disorders in the 1990s has been estimated to be $\$ 42.3 \mathrm{bn}$ (£27.3bn; €37.3bn). ${ }^{5}$ Women have a higher prevalence of anxiety disorders than men ${ }^{6}$ and the onset for most anxiety disorders is commonly in adolescence or young adulthood. However, the incidence of anxiety disorders remains substantial in midlife, and new cases continue to arise into later life, especially in the case of generalized anxiety disorder. ${ }^{7}$ Although numerous pharmacologic and non-pharmacologic therapies are available, remission is not always possible. Many people have persistent symptoms despite use of first line treatments. ${ }^{8}$

Given the substantial personal and societal burden from anxiety and the problem of treatment resistance, it is imperative to identify modifiable risk factors for anxiety disorders and symptoms. One important environmental exposure that may be related to anxiety is air pollution. Specifically, exposure to particulate matter air pollution may induce or exacerbate anxiety through increased oxidative stress and systemic inflammation ${ }^{9-17}$ or through promotion or aggravation of chronic disease. ${ }^{18-32}$ Though there is a small set of studies considering the association between air pollution and mental health outcomes, ${ }^{33-44}$ we are aware of only two small 
studies that considered anxiety, and neither looked at total particulate matter. The first $(n=1002)$ reported that ozone levels in the prior week were associated with anxiety symptoms, ${ }^{33}$ whereas the second $(n=100)$ reported that cumulative exposure to airborne manganese was associated with anxiety symptoms. ${ }^{44}$ Epidemiologic research on the relation between exposure to particulate matter and anxiety is clearly lacking; we evaluated this association in a large prospective cohort study. Specifically, we hypothesized that higher exposure to particulate matter would be associated with a greater risk of high symptoms of anxiety.

The most biologically relevant period of exposure is currently unknown. If particulate matter induces anxiety through chronic oxidative stress, inflammation, or induction of chronic disease, long term cumulative exposure is most likely relevant. If particulate matter aggravates an existing propensity for anxiety symptoms, through either aggravation of chronic disease or transient changes in oxidative stress or inflammation, exposures closer to the time of symptom assessment may be relevant. Therefore, we considered the association between high anxiety symptoms and exposure to particulate matter averaged over five periods prior to the assessment of anxiety symptoms, specified a priori, ranging from a measure of long term, cumulative exposure (prior 15 years) to a measure of recent exposure (prior month).

\section{Methods}

Study population

The Nurses' Health Study is a prospective cohort study of women that began in 1976. A total of 121701 married registered nurses, ages 30-55, residing in 11 states, were originally enrolled; at least 10 participants now reside in each of the 48 continental states. All participants are mailed follow-up questionnaires every two years, with a response rate of greater than $90 \%$ for each questionnaire..$^{45}$ As such, we receive updated information on residential address biennially, and we have geocoded all home addresses 1986 to 2007 within the contiguous United States to obtain latitude and longitude, allowing estimation of exposure to particulate air pollution. The Crown-Crisp index phobic anxiety scale, one of six scales from the Crown-Crisp experiential index, is a measure of anxiety symptom levels and was included in the 1988 and 2004 questionnaires. As our exposure data were available from 1988 onward (inclusive), we used data from the 2004 Crown-Crisp index phobic anxiety scale as our outcome measure of anxiety. The nurses' provided implied informed consent by completion and return of each questionnaire.

\section{Residential proximity to roadways}

Using geographic information software (ArcGIS, Version 10.2; Esri, CA), we computed distance from the residential address of each participant in 2002, up to $500 \mathrm{~m}$, with a street level geocoding match to the nearest US census feature class code A1 (limited access to primary roads with defined exits and divided directions of travel, that is, interstate highways), A2 (primary major, non-interstate highways and major roads without access restrictions), or A3 (smaller, secondary roads, typically with more than two lanes) road segment. Distance to a major road is a commonly used proxy for traffic related exposures, including traffic related air pollution (which typically contains a high proportion of ultrafine particles, those $<0.1 \mu \mathrm{m}$ in diameter). ${ }^{46-48}$ We classified distance to the nearest major road a priori as $<50 \mathrm{~m}, 50$ to $<200 \mathrm{~m}$, or $\geq 200 \mathrm{~m}$, based on the observed pattern of particulate concentrations with increasing distance ${ }^{47-49}$ and the distribution of roadway proximity in our sample.

\section{Particulate matter air pollution}

We used spatiotemporal prediction models yielding monthly estimates of exposure to particulate matter $<10 \mu \mathrm{m}\left(\mathrm{PM}_{10}\right)$ and $<2.5 \mu \mathrm{m}\left(\mathrm{PM}_{2.5}\right.$ or fine particulate matter) in aerodynamic diameter from January 1988 onward at the residential address with at least a zip code level geocoding match for each participant to derive multiple exposure metrics for each participant. These models cover the contiguous United States and are extensions of previously described models covering a more limited area. ${ }^{50-52}$ Data used in these models included nationwide monitor data, geographic data (for example, distance to major roadway, population density, elevation, proportion of urban land use, point or area source emissions), and meteorological data (for example, temperature, wind speed, precipitation, barometric pressure). As nationwide $\mathrm{PM}_{2.5}$ monitor data were unavailable prior to 1999 , our pre-1999 estimates of $\mathrm{PM}_{2.5}$ exposure were derived from a model that estimates the predicted ratio of $\mathrm{PM}_{2.5}$ to $\mathrm{PM}_{10}$ between 1988 and 1999; to get $\mathrm{PM}_{2.5}$ predictions we combined the results of this model with estimates from the $\mathrm{PM}_{10}$ model. We derived estimates of exposure to coarse $\left(\mathrm{PM}_{2.5-10}\right)$ particulate matter by taking the difference between $\mathrm{PM}_{10}$ and $\mathrm{PM}_{2.5}$ estimates. For the current analyses we used these models to derive measures of average exposure to $\mathrm{PM}_{2.5}$ and $\mathrm{PM}_{2.5-10}$, at the residential address of each participant for several exposure periods, including the average exposure between 1 January 1988 and 31 December 2003, and over the 1, 3, 6, and 12 calendar months prior to the participant's 2004 questionnaire cycle return date (that is, for a questionnaire returned in July 2004, we use the average exposure in June 2004 for the one month averaging period).

\section{Anxiety symptoms}

The Crown-Crisp index phobic anxiety scale consists of eight self rated questions about fearfulness and desire for avoidance of common situations or environments (that is, having "unreasonable fear of enclosed spaces", being "scared of heights", disliking "going out alone", feeling "panicky in crowds", feeling "more relaxed indoors", feeling "uneasy traveling on buses or trains") and tendency to worry (that is, "about getting some incurable illness", worrying "unduly when relatives are late coming home"); total possible index scores range from 0-16 points, with higher scores indicating more anxiety. ${ }^{53}$ We required complete data on all eight items 
to compute a total score. The Crown-Crisp index phobic anxiety scale has been shown to differentiate between people with general anxiety or phobias from those with other psychiatric conditions and healthy comparison participants $\mathrm{s}^{534}$ and has been used in population based research. ${ }^{55-61}$ For primary analyses, we dichotomized Crown-Crisp index phobic anxiety scale scores from 2004 and considered those with a score of 6 points or more to have high symptoms of anxiety, as prior work suggests that this cut-off represents a clinically important threshold..$^{58} 61$

\section{Covariates}

Covariates included in all models were selected a priori because they were thought to be potential confounders or proxies for potential confounders (for example, socioeconomic status) and include calendar month of questionnaire return (categorical month), educational attainment (RN, BA, MA, or PhD), husband's educational attainment ( $\leq 12$ years, $12-16$ years, $>16$ years, not applicable, missing), age, age squared, married or has a partner (yes/no), employment status (yes/no), physical activity $(<12,12$ to $30,>30$ metabolic equivalent task hours per week), three residential census tract level characteristics (percent white race/ethnicity, percent of adults without a high school diploma, and median home value; in fourths), region of residence (north east, south, midwest, west), residence within a metropolitan statistical area (yes/no), and social support ${ }^{62}$ (low, low-medium, medium, high social networks). Many covariates were assessed at multiple cycles; we used the value at the 1988 or closest available questionnaire when considering the 1988-2003 averaging period and the 2002 or closest available questionnaire in models considering roadway proximity or particulate matter exposures within the year prior to the 2004 questionnaire return. With the exception of month of questionnaire return, we used missing indicators when covariate data were missing for more than $2 \%$ of our sample and replaced missing data with median or mode values when covariate data were missing in less than $2 \%$ of our sample.

\section{Primary analysis}

For each model we restricted our analytical sample to people with 2004 Crown-Crisp index phobic anxiety scale scores and relevant exposure data. We used separate logistic regression models to estimate the association between each exposure and high anxiety symptoms (Crown-Crisp index phobic anxiety scale score $\geq 6$ ). For models considering exposure to particulate matter, we evaluated the shape of the dose-response curve using penalized splines and report analyses using both fifths of exposure and linear terms. As exposures to particulate matter are correlated across averaging periods (see supplementary table e1), it is challenging to determine which exposure periods are most relevant when multiple periods appear associated with anxiety. Therefore, we also considered mutually adjusted models including either 1988-2003 and past one month or past 12 month and past one month exposures to particulate matter parameterized using penalized splines to tackle whether long term or short term exposures were more relevant when we observed an association between anxiety and multiple averaging periods. To avoid the potential for differences in the variability of metrics for exposure to particulate matter across the two averaging periods to influence the findings, we used $z$ score transformations of each of the particulate matter exposures (that is, one month, 12 months, and 1988-2003) in the mutually adjusted models.

\section{Sensitivity analyses}

We conducted several sensitivity analyses to examine the robustness of our primary findings, including use of alternate categorizations for roadway proximity $(<50 \mathrm{~m}$, 50-200 m, and $>200 \mathrm{~m}$ from A1 or A2 roadways; $<100 \mathrm{~m}, 100-300 \mathrm{~m}$, and $>300 \mathrm{~m}$ from either A1, A2, or $\mathrm{A} 3$ roadways or A1 or A2 only roadways; and as a continuous variable for distance from A1, A2, or A3 roadways using a linear or spline parameterization within the range of 0 to $500 \mathrm{~m}$ ); additional adjustment for individual level covariates often correlated with anxiety symptoms but which were not expected to be confounders, including physical functioning 63 (high, low), self rated health (excellent or very good, poor to average), number of major medical comorbidities $(\geq 3,<3)$, alcohol consumption (non-drinker, <3, 3-6, $>7$ alcoholic drinks per week), body mass index (normal, overweight, obese), and smoking status (never, former, current); restriction to non-movers (to reduce misclassification of exposure measures given some participants changed addresses but exact move dates are unknown); restriction to those who returned the questionnaire within three months of the initial mailing (to reduce misclassification of short term exposure measures, which are based on the return date for the questionnaire); restriction to those living in a metropolitan area, defined using rural-urban commuting $\operatorname{codes}^{64}$ (to reduce potential confounding by urban versus rural environments); restriction to non-Hispanic white participants $(96.7 \%$ of the sample, to allay concerns about confounding by race); use of negative binomial regression, which considers Crown-Crisp index phobic anxiety scale scores as count data and is similar to, but more appropriate and generally more conservative than Poisson regression when dealing with over-dispersed count data; and use of an alternate case definition with improved sensitivity but less specificity where we considered all people with a Crown-Crisp index phobic anxiety scale score of 6 or more and/or self report of use of anti-anxiety or antidepressant medications on the 2004 questionnaire to have high anxiety symptoms.

\section{Effect modification}

We used multiplicative interaction terms and likelihood ratio tests to evaluate evidence for effect modification by several factors. These were residence within a metropolitan statistical area (yes/no) and United States census region (north east, south, midwest, west), as particulate matter composition may vary spatially; prevalent reactive airway disease (chronic obstructive pulmonary disease or asthma), atrial fibrillation, heart 
failure, or multiple major medical conditions at the time of anxiety assessment (yes/no), as particulate matter may lead to anxiety through aggravation of symptoms of common medical conditions; age (over or under 65 at the time of anxiety assessment), as anxiety incidence and prevalence change with age; and 1988 Crown-Crisp index phobic anxiety scale score $(0-1,2-5$, $\geq 6)$, given that high anxiety symptoms may have been present prior to the 2004 assessment. To limit the number of tests, we evaluated effect modification only when primary analyses indicated a main effect, and then only for the averaging period we judged to have the strongest association. We made no other adjustments to account for multiple comparisons. We report $95 \%$ confidence intervals and consider a $\mathrm{P}$ value $<0.05$ to be statistically significant. All analyses were conducted using SAS, Version 9.3 or R, Version 3.0.1.

\section{Results}

Sample sizes differed across analyses, based on availability of valid estimates on exposure $(n=63677$ for roadway proximity analyses, $\mathrm{n}=69966$ for $1988-2003$ average analyses of exposure to particulate matter, and $\mathrm{n}=71271$ for all other analyses). Among the largest group $(n=71271)$, at the time of completion of the Crown-Crisp index phobic anxiety scale the women in our sample were on average aged 70 (SD 7, range 57-85) years, $16 \%(n=11320)$ of them reported current use of antidepressants and/or anti-anxiety medications, and the prevalence of high anxiety symptoms (Crown-Crisp index phobic anxiety scale $\geq 6$ ) was $15 \%$ ( $n=10818$ ) (fig 1 ). Table 1 shows the socioeconomic characteristics of this sample. Of the 63677 with valid estimates of 2002 residential roadway proximity, distance to the nearest major road was $>200 \mathrm{~m}$ for $59.0 \%(\mathrm{n}=37545), 50-200 \mathrm{~m}$ for $26.4 \%$ ( $n=16802)$, and $<50 \mathrm{~m}$ for $14.7 \%$ ( $\mathrm{n}=1120)$. In line with temporal trends, mean estimates for exposure to $\mathrm{PM}_{2.5}$ and $\mathrm{PM}_{2.5-10}$ were highest for the 1988-2003 exposure period (Table 2 and supplementary table e1). For example, the mean (SD) of exposures to $\mathrm{PM}_{2.5-10}$ particulate matter was $9.0 \mu \mathrm{g} / \mathrm{m}^{3}$ (SD 4.1) in 1988-2003 compared with $7.3\left(4.8 \mu \mathrm{g} / \mathrm{m}^{3}\right)$ for the one month averaging period. Similarly, the mean (SD) of exposures to $\mathrm{PM}_{2.5}$ particulate matter was $13.8\left(2.8 \mu \mathrm{g} / \mathrm{m}^{3}\right)$ in $1988-2003$

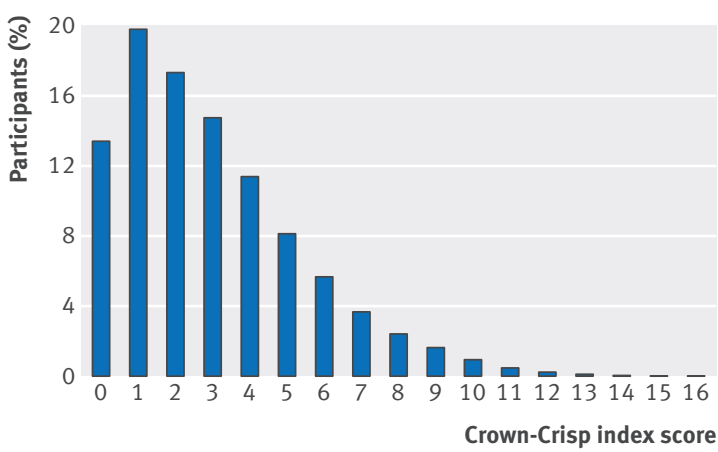

Fig 1 Distribution of Crown-Crisp index phobic anxiety scale scores among eligible participants of Nurses' Health Study
Table 1 | Socioeconomic characteristics from 2002 or nearest available Nurses' Health Study questionnaire

Characteristics

No $(\%)$ of women $(n=71271)$

Educational attainment:

\begin{tabular}{ll}
\hline Registered nurse & $44907(63.0)$ \\
\hline Bachelors degree & $13368(18.8)$ \\
\hline Masters degree or PhD & $6607(9.3)$ \\
\hline Missing & $6389(9.0)$ \\
\hline
\end{tabular}

Husband's education:

High school degree or less 24664 (34.6)

College degree 16321 (22.9)

Professional or graduate school 13978 (19.6) degree

Not applicable $\quad 4977(7.0)$

Missing 11331 (15.9)

Marital/partner status:

\begin{tabular}{ll}
\hline No current life partner & $20521(28.8)$ \\
\hline Current life partner & $49855(70.0)$ \\
\hline Missing & $895(1.3)$ \\
\hline Employment status: & \\
\hline $\begin{array}{l}\text { Currently not employed outside } \\
\text { the home }\end{array}$ & $46617(65.4)$ \\
\hline $\begin{array}{l}\text { Currently employed outside the } \\
\text { home }\end{array}$ & $23891(33.5)$ \\
\hline Missing & $763(1.1)$ \\
\hline
\end{tabular}

Physical activity:

\begin{tabular}{ll}
\hline$<12 \mathrm{METS} /$ week & 32161 (45.1) \\
\hline
\end{tabular}

12 to $<30 \mathrm{METS} /$ week $27582(38.7)$

$\geq 30 \mathrm{METS} /$ week $11290(15.8)$

Missing $238(0.3)$

Percent of census tract, white race/ethnicity:

\begin{tabular}{ll}
\hline$<85 \%$ & $15627(21.9)$ \\
\hline $85 \%$ to $<94 \%$ & $18858(26.5)$ \\
\hline $94 \%$ to $<97 \%$ & $15992(22.4)$ \\
\hline$\geq 97 \%$ & $20789(29.2)$ \\
\hline Missing & $5(0.0)$
\end{tabular}

Percent of census tract, adult residents without a high school diploma:

\begin{tabular}{ll}
\hline$<5 \%$ & $8911(12.5)$ \\
\hline $5 \%$ to $<10 \%$ & $19211(27.0)$ \\
\hline $10 \%$ to $<15 \%$ & $18037(25.3)$ \\
\hline$\geq 15 \%$ & $25107(35.2)$ \\
\hline Missing & $5(0.0)$ \\
\hline
\end{tabular}

Median home value (\$):

\begin{tabular}{ll}
\hline$<95000$ & $16934(23.8)$ \\
\hline 95000 to $<135000$ & $18143(25.5)$ \\
\hline 135000 to $<210000$ & $19959(28.0)$ \\
\hline$\geq 210000$ & $16139(22.7)$ \\
\hline Missing & $96(0.0)$ \\
\hline Region of residence: & \\
\hline North east & $35040(49.2)$ \\
\hline Midwest & $12355(17.3)$ \\
\hline West & $10199(14.3)$ \\
\hline South & $13677(19.2)$ \\
\hline Residence within a metropolitan statistical district: \\
\hline Yes & $64648(90.7)$ \\
\hline No & $6623(9.3)$ \\
\hline Social support (Berkman-Syme index): \\
\hline Low & $4264(6.0)$ \\
\hline Low-medium & $20148(28.3)$ \\
\hline Medium & $10283(14.4)$ \\
\hline High & $28310(39.7)$ \\
\hline Missing & $8266(11.6)$ \\
\hline S1.00
\end{tabular}

$\$ 1.00$ ( $€ 0.65 ; € 0.88)$. 
Table 2 | Odds ratio (95\% confidence interval) for $10 \mu \mathrm{g} / \mathrm{m}^{3}$ increase in exposure to $\mathrm{PM}_{2.5}$ over multiple averaging periods and high symptoms of anxiety in participants of Nurses' Health Study

\begin{tabular}{llll} 
Period & Mean (SD) $\mathbf{P M}_{2.5}\left(\mu \mathrm{g} / \mathrm{m}^{3}\right)$ & Odds ratio* $(95 \% \mathrm{CI})$ & P value \\
\hline 1 month & $12.74(4.18)$ & $1.12(1.06$ to 1.19$)$ & 0.0001 \\
\hline 3 months & $12.13(3.40)$ & $1.13(1.06$ to 1.21$)$ & 0.0004 \\
\hline 6 months & $11.59(2.77)$ & $1.14(1.05$ to 1.23$)$ & 0.002 \\
\hline 12 months & $11.38(2.60)$ & $1.15(1.06$ to 1.25$)$ & 0.001 \\
\hline $1988-2003$ & $13.75(2.82)$ & $1.09(1.01$ to 1.18$)$ & 0.03 \\
\hline
\end{tabular}

$\mathrm{PM}_{2.5}=$ particulate matter $<2.5 \mu \mathrm{m}$ in diameter

*Adjusted for month of questionnaire return, nurse's education, husband's education, age, age squared, whether the nurse has a partner, employment status, physical activity, percent of residential census tract that is white, percent of residential census tract adults who lack a high school education, median home value of residential census tract, geographic region, residence within a metropolitan statistical area, and social support.
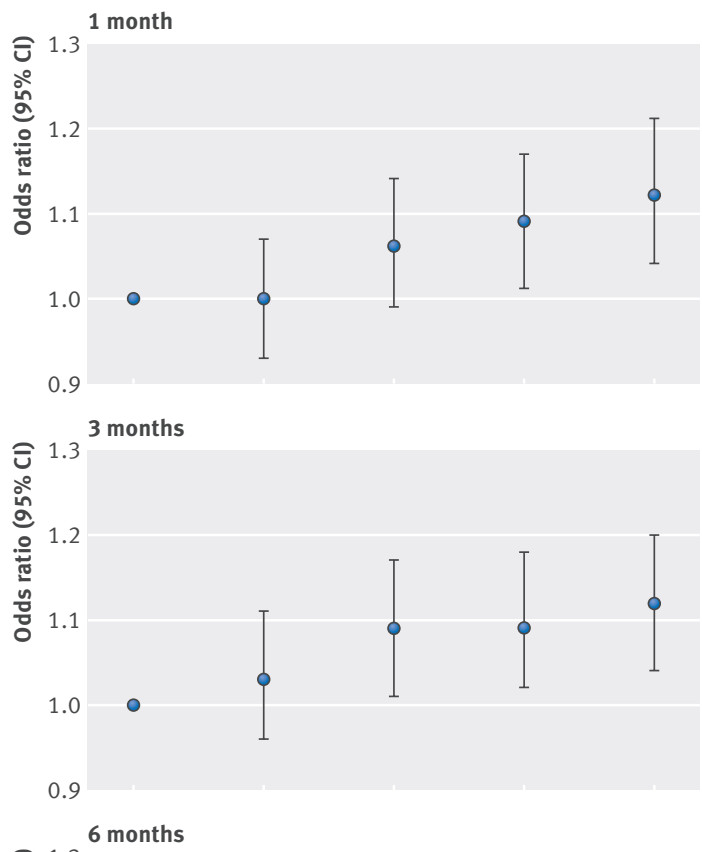

compared with $12.7\left(4.2 \mu \mathrm{g} / \mathrm{m}^{3}\right)$ for the one month averaging period.

\section{Residential proximity to roadways}

Nurses who lived 50 to $200 \mathrm{~m}$ from the nearest major road were more likely to have increased Crown-Crisp index phobic anxiety scale scores than those living $>200$ m away (adjusted odds ratio 1.06, 95\% confidence interval 1.01 to $1.12 ; \mathrm{P}=0.03)$. However, there was no evidence of a dose-response pattern, as those living within $50 \mathrm{~m}$ of the nearest major road did not have increased odds (adjusted odds ratio 1.01, 0.95 to 1.08; $\mathrm{P}=0.74$ ). Findings of all sensitivity analyses were similar or more uniformly null (see supplementary table e2 and figure e1).

\section{Particulate matter}

We observed associations between higher $\mathrm{PM}_{2.5}$ and high anxiety across several averaging periods. Given evidence for slightly non-linear dose-response patterns in some averaging periods (see supplementary figure e2), we report associations with both fifths of exposure (fig 2) and per $10 \mu \mathrm{g} / \mathrm{m}^{3}$ increase in exposure (table 2). Notably, while associations were similar across 1, 3, 6, and 12 month averaging periods, associations for the 1988-2003 averaging period were weaker than for the shorter averaging periods. All sensitivity analyses were reasonably consistent with our primary models (see supplementary tables e4 to e10). Mutually adjusted models suggest that these associations were primarily driven by an association between anxiety and shorter averaging periods (fig 3). There was little evidence to support an association between high anxiety and exposure to $\mathrm{PM}_{2.5-10}$ in either our primary (see supplementary table e3 and figure e3) or our sensitivity analyses (see supplementary tables e4 to e10). We did not observe significant effect modification of the association with one month $\mathrm{PM}_{2.5}$ by any of the proposed variables (all likelihood ratio test $\mathrm{P}>0.16$ ).

Fig 2 Adjusted* odds ratios (95\% confidence intervals) between particulate matter $<2.5 \mu \mathrm{m}$ in diameter $\left(\mathrm{PM}_{2.5}\right)$ considered using fifths of exposure, over multiple averaging periods and high symptoms of anxiety in Nurses' Health Study. *Adjusted for month of questionnaire return, nurse's education, husband's education, age, age squared, whether the nurse has a partner, employment status, physical activity, percent of residential census tract that is white, percent of residential census tract adults who lack a high school education, median home value of residential census tract, geographic region, residence within a metropolitan statistical area, and social support 

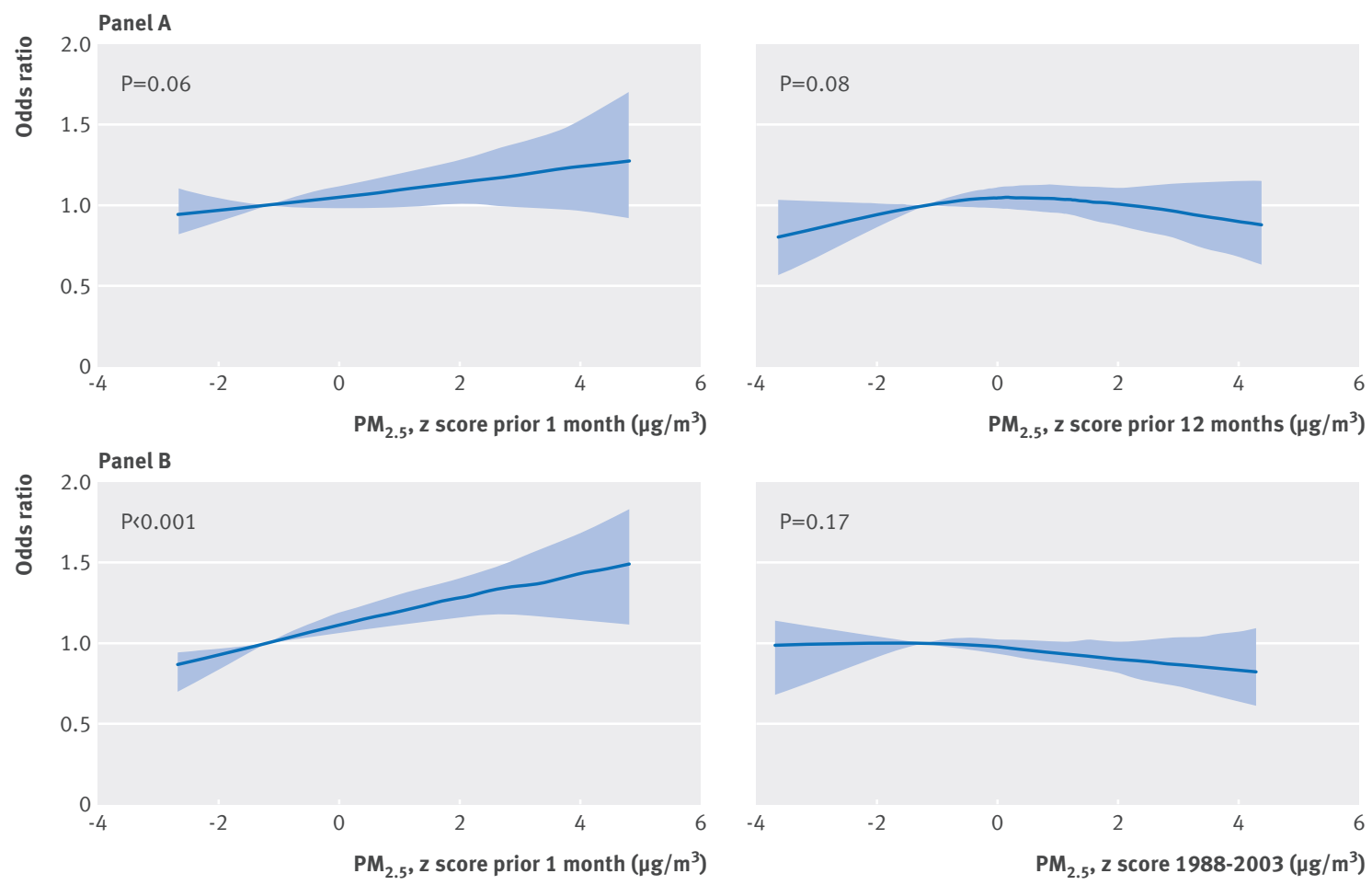

Fig 3 | Odds ratio (95\% confidence interval) exposure to particulate matter $<2.5 \mu \mathrm{m}$ in diameter $\left(\mathrm{PM}_{2.5}\right)$ on high symptoms of anxiety in Nurses' Health Study when multiple averaging periods are included in same model, parameterized using splines. Results of a model including both z transformed prior 12 month and $\mathrm{z}$ transformed prior one month $\mathrm{PM}_{2.5}$ exposure (panel A), and including both the $z$ transformed prior 15 years (1988-2003) and $z$ transformed prior one month $\mathrm{PM}_{2.5}$ exposure (panel $\mathrm{B}$ ). The 10th centile was chosen as the reference level for the corresponding exposure of interest. $P$ values indicate strength of evidence for an association (versus no association) for exposure to particulate matter, over its entire range, on high anxiety

\section{Discussion}

Our data support an association between exposure to particulate matter of $<2.5 \mu \mathrm{m}$ in diameter $\left(\mathrm{PM}_{2.5}\right)$ but not 2.5 to $10 \mu \mathrm{m}$ in diameter $\left(\mathrm{PM}_{2.5-10}\right)$ or proximity to roadways, and high symptoms of anxiety. The association between $\mathrm{PM}_{2.5}$ and high anxiety seems primarily driven by a relation with shorter term average exposures to $\mathrm{PM}_{2.5}$. There is little evidence to suggest differences in this association by demographic, geographic, or health related characteristics.

\section{Limitations and strengths of this study}

Our study has some limitations. We were unable to consider the clinical diagnosis of specific anxiety disorders. However, prior epidemiologic work suggests that CrownCrisp index scores are a valid ${ }^{1617}$ and clinically relevant measure, as they are associated with accelerated aging, ${ }^{58}$ ischemic heart disease, ${ }^{56}$ and sudden cardiac death. ${ }^{55} 5965$ We were unable to consider the association between anxiety and fluctuations in $\mathrm{PM}_{2.5}$ over periods of less than one month, or short term fluctuations in ultrafine particulate matter (residential distance to a major road as a proxy measure is necessarily a longer term indicator). It is possible that the association we observed with $\mathrm{PM}_{2.5}$ is attributable, in whole or in part, to a correlation between $\mathrm{PM}_{2.5}$ and another exposure. Ambient ozone and noise are unlikely, although still possible, candidates given relatively weak correlations with $\mathrm{PM}_{2.5}{ }^{66}{ }^{68}$ Similarly, we cannot preclude a contribution of other pollutants that share sources with $\mathrm{PM}_{2.5}$ (for example, nitrogen dioxide, sulphur dioxide).${ }^{67}$ Our models provide predictions of exposure at each participant's residential address. Given lack of information on the activity pattern of each participant, this could lead to bias due to misclassification. Nevertheless, any such bias is expected to be towards the null ${ }^{69}$ and so would not account for the observed associations with $\mathrm{PM}_{2.5}$. Furthermore, as environmental regulations set acceptable exposure limits based on outdoor measures, we believe that this exposure is most relevant from the public health perspective. Our study considered only women; it is possible that our results may not be generalizable to men. Similarly, the women in our study were relatively old. Given that advancing age is related to lower physiologic reserve, ${ }^{70}$ it is possible that our results would not generalize to younger age groups.

Our study also has several strengths. While discussed previously as a limitation, our focus on anxiety symptoms is also a strength. Our data suggest a short term, potentially reversible relation between exposures to particulate matter and severity of anxiety symptoms, which may not have been identified if we had focused exclusively on anxiety disorders. Although the relevant exposure period was unknown, we considered multiple averaging periods of exposure; this ultimately suggested that short term exposure to $\mathrm{PM}_{2.5}$ may be the 
most relevant exposure. We had access to a large prospective cohort, allowing adequate power to detect modest but meaningful associations. Attrition was small and any potential selection bias due to informative drop-out would be expected to be a downward bias, and so our estimate of an adverse association with $\mathrm{PM}_{2.5}$ may be an underestimate. We were able to adjust for many socioeconomic and sociodemographic factors, which we thought to be the strongest potential confounders. Our results were robust to multiple sensitivity analyses.

\section{Comparison to other studies and discussion of potential mechanism}

To our knowledge this is the first study to consider the association between exposure to particulate matter and anxiety. However, our findings are consistent with two prior studies of other air pollutants and anxiety, ${ }^{3344}$ as well as work suggesting associations between air pollution and other related, but distinct, mental health outcomes, including depressive symptoms, ${ }^{34} 35$ psychiatric emergency, ${ }^{36-38}$ emergency room visits for depression or suicide, ${ }^{39-42}$ and reported suicide. ${ }^{43}$

Exposure to particulate matter could induce or exacerbate anxiety through increased oxidative stress and inflammation or through inducing or aggravating major medical conditions. Inflammation and oxidative stress have been hypothesized to contribute to the incidence and severity of anxiety. ${ }^{910}$ Several toxicological studies have shown that oxidative stress ${ }^{71-75}$ or systemic inflammation 7576 induces anxiety-like behaviors in mice and rats. These results are consistent with cross sectional associations between anxiety symptoms and inflammatory markers in people, ${ }^{77-79}$ as well as epidemiologic findings linking $\mathrm{C}$ reactive protein, an inflammatory marker, to generalized anxiety disorder in patients with stable coronary heart disease. ${ }^{80}$ Inhaled particulate matter may therefore contribute to anxiety through induction of systemic $^{11-17}$ or brain based ${ }^{81-83}$ oxidative stress and inflammation. Alternatively, anxiety may occur as a result of a respiratory or cardiac medical condition. Reduced lung function, reactive airway diseases such as asthma and chronic obstructive pulmonary disease, atrial fibrillation, and congestive heart failure are associated with an increased prevalence of anxiety symptoms or disorders. ${ }^{18-23}$ These associations are likely mediated by fear and misinterpretation of symptoms, although an impact of the stress of dealing with major medical conditions or a purely physiological reaction to oxygenation changes associated with dysfunctional breathing and/or heart function may also contribute. ${ }^{84-89}$ As particulate matter has been linked to multiple medical conditions and aggravation of symptoms, ${ }^{24-32}$ particulate air pollution may also contribute to anxiety through this alternative mechanism. While our findings are consistent with the oxidative stress/inflammatory mechanistic hypothesis, our data do not support the hypothesis that particles promote anxiety through induction or aggravation of medical conditions, as there was no difference in the association by whether or not people had major medical comorbidities. The reported association with $\mathrm{PM}_{2.5}$, but not $\mathrm{PM}_{2.5-10}$ may be related to size related differences in toxicity, which are likely a function of differences in lung penetrability, surface area, and composition by particle size. ${ }^{90-94}$

\section{Conclusions}

Anxiety is a common and costly disorder. Our data support an association between exposure to $\mathrm{PM}_{2.5}$, a common environmental exposure, and high symptoms of anxiety. If confirmed, our findings may have policy and clinical implications, as it is possible that reductions in exposure to $\mathrm{PM}_{2.5}$, through changes to regulations or individual behavior, may help reduce anxiety symptoms. Future work directly evaluating this possibility is warranted.

We thank Peter James for his help with the Rural Urban Commuting Area codes

Contributors: All authors made substantial contributions to the conception and design (MCP, MGW, MAK, JEH, OIO, and FL), acquisition of the data (FL, JEH), or analysis and interpretation (MCP, MGW, MAK, $\mathrm{JEH}, \mathrm{OIO}$, and FL). MCP drafted the article and all other authors revised it critically for important intellectual content. MCP is guarantor. All authors had full access to all of the data in the study and can take responsibility for the integrity of the data and the accuracy of the data analysis.

Funding: This work was supported by grants from the National Institute of Environmental Health Sciences (R21 ES019982, R01 ES017017). MCP was supported by a training grant from the National Institute of Aging (T32 AG027668). The funding agencies had no role in the design and conduct of the study; collection, management, analysis, and interpretation of the data; preparation, review, or approval of the manuscript; or decision to submit the manuscript for publication. The authors were independent of the study funders.

Competing interests: All authors have completed the ICMJE uniform disclosure form at www.icmje.org/coi_disclosure.pdf (available on request from the corresponding author) and declare: no support from any organization for the submitted work; no financial relationships with any organizations that might have an interest in the submitted work in the previous three years; no other relationships or activities that could appear to have influenced the submitted work.

Ethical approval: This study was approved by the institutional review board of the Brigham and Women's Hospital and the human subjects committee of the Harvard School of Public Health.

Data sharing: The statistical code is available from the corresponding author at melindacpower@gmail.com.

Transparency: The lead author (MCP) affirms that the manuscript is an honest, accurate, and transparent account of the study being reported; that no important aspects of the study have been omitted; and that any discrepancies from the study as planned (and, if relevant, registered) have been explained.

This is an Open Access article distributed in accordance with the Creative Commons Attribution Non Commercial (CC BY-NC 4.0) license, which permits others to distribute, remix, adapt, build upon this work non-commercially, and license their derivative works on different terms, provided the original work is properly cited and the use is non-commercial. See: http://creativecommons.org/licenses/ by-nc/4.0/.

American Psychiatric Association. Diagnostic and statistical manual of mental disorders, fifth edition (DSM-V). APA, 2013.

2 Kessler RC, Aguilar-Gaxiola S, Alonso J, Chatterji S, Lee S, Ormel J, et al. The global burden of mental disorders: an update from the WHO World Mental Health (WMH) surveys. Epidemiol Psichiatr Soc 2009; 18:23-33.

3 Lepine JP. The epidemiology of anxiety disorders: prevalence and societal costs. / Clin Psychiatry 2002;63:4-8.

4 Whiteford HA, Degenhardt L, Rehm J, Baxter AJ, Ferrari AJ, Erskine HE, et al. Global burden of disease attributable to mental and substance use disorders: findings from the global burden of disease study 2010 Lancet 2013:382:1575-86. 
5 Greenberg PE, Sisitsky T, Kessler RC, Finkelstein SN, Berndt ER, Davidson JR, et al. The economic burden of anxiety disorders in the 1990s. / Clin Psychiatry 1999:60:427-35.

6 McLean CP, Asnaani A, Litz BT, Hofmann SG. Gender differences in anxiety disorders: prevalence, course of illness, comorbidity and burden of illness. I Psychiatr Res 2011;45:1027-35.

7 Kessler RC, Berglund P, Demler O, Jin R, Merikangas KR, Walters EE. Lifetime prevalence and age-of-onset distributions of DSM-IV disorders in the national comorbidity survey replication. Arch Gen Psychiatry 2005:62:593-602

8 Lanouette NM, Stein MB. Advances in the management of treatment-resistant anxiety disorders. Focus (Am Psychiatr Publ) 2010;8:501-24.

9 Salim S, Chugh G, Asghar M. Inflammation in anxiety. Adv Protein Chem Struct Biol 2012;88:1-25

10 Hou R, Baldwin DS. A neuroimmunological perspective on anxiety disorders. Hum Psychopharmacol 2012;27:6-14

11 Sørensen M, Daneshvar B, Hansen M, Dragsted LO, Hertel O, Knudsen L, et al. Personal PM2.5 exposure and markers of oxidative stress in blood. Environ Health Perspect 2003:111:161-5.

12 Dagher Z, Garçon G, Billet S, Gosset P, Ledoux F, Courcot D, et al. Activation of different pathways of apoptosis by air pollution particulate matter (PM2.5) in human epithelial lung cells (1132) in culture. Toxicology 2006;225:12-24.

13 Kim JY, Mukherjee S, Ngo L, Christiani DC. Urinary 8-hydroxy-2' deoxyguanosine as a biomarker of oxidative DNA damage in workers exposed to fine particulates. Environ Health Perspect 2004;112:666-71

14 Hovatta I, Tennant RS, Helton R, Marr RA, Singer O, Redwine JM, et al. Glyoxalase 1 and glutathione reductase 1 regulate anxiety in mice. Nature 2005:438:662-6.

15 Brook RD, Rajagopalan S, Pope CA, BrookJR, Bhatnagar A, Diez-Roux AV, et al. Particulate matter air pollution and cardiovascular disease: an update to the scientific statement from the American Heart Association. Circulation 2010;121:2331-78.

16 Dubowsky SD, Suh H, Schwartz J, Coull BA, Gold DR. Diabetes, obesity, and hypertension may enhance associations between air pollution and markers of systemic inflammation. Environ Health Perspect 2006;114:992-8.

17 Bind MA, Baccarelli A, Zanobetti A, Tarantini L, Suh H, Vokonas P, et al. Air pollution and markers of coagulation, inflammation, and endothelial function: associations and epigene-environment interactions in an elderly cohort. Epidemiology 2012;23:332-40.

18 Spitzer C, Gläser S, Grabe HI, Ewert R, Barnow S, Felix SB, et al. Mental health problems, obstructive lung disease and lung function: findings from the general population. J Psychosom Res 2011;71:174-9.

19 Scott KM, Von Korff M, Ormel J, Zhang M-y, Bruffaerts R, Alonso J, et al. Mental disorders among adults with asthma: Results from the world mental health survey. Gen Hosp Psychiatry 2007;29:123-33.

20 Brenes GA. Anxiety and chronic obstructive pulmonary disease: Prevalence, impact, and treatment. Psychosom Med 2003;65:963-70

21 Yohannes AM, Willgoss TG, Baldwin RC, Connolly MJ. Depression and anxiety in chronic heart failure and chronic obstructive pulmonary disease: Prevalence, relevance, clinical implications and management principles. Int J Geriatr Psychiatry 2010;25:1209-21.

22 Thrall G, Lip GYH, Carroll D, Lane D. Depression, anxiety, and quality of life in patients with atrial fibrillation. CHEST 2007:132:1259-64.

23 Lane DA, Langman CM, Lip GYH, Nouwen A. Illness perceptions, affective response, and health-related quality of life in patients with atrial fibrillation. I Psychosom Res 2009;66:203-10.

24 Ling SH, van Eeden SF. Particulate matter air pollution exposure: Role in the development and exacerbation of chronic obstructive pulmonary disease. Int J Chron Obstruct Pulmon Dis 2009;4:233-43.

25 Faustini A, Stafoggia M, Cappai G, Forastiere F. Short-term effects of air pollution in a cohort of patients with chronic obstructive pulmonary disease. Epidemiology 2012;23:861-79.

26 Delfino RJ. Epidemiologic evidence for asthma and exposure to air toxics: Linkages between occupational, indoor, and community air pollution research. Environ Health Perspect 2002;110:573.

27 Künzli N, Bridevaux P-O, Liu L-JS, Garcia-Esteban R, Schindler C, Gerbase MW, et al. Traffic-related air pollution correlates with adult-onset asthma among never-smokers. Thorax 2009;64:664-70.

28 Link MS, Luttmann-Gibson H, Schwartz J, Mittleman MA, Wessler B, Gold DR, et al. Acute exposure to air pollution triggers atrial fibrillation. J Am Coll Cardiol 2013;62:816-25.

29 Pope CA. Review: Epidemiological basis for particulate air pollution health standards. Aerosol Sci Technol 2000:32:4-14.

30 Rich DQ, Mittleman MA, Link MS, Schwartz J, Luttmann-Gibson H, Catalano PJ, et al. Increased risk of paroxysmal atrial fibrillation episodes associated with acute increases in ambient air pollution. Environ Health Perspect 2006:114:120-3.

31 Kesavachandran C, Pangtey BS, Bihari V, Fareed M, Pathak MK, Srivastava AK, et al. Particulate matter concentration in ambient air and its effects on lung functions among residents in the national capital region, India. Environ Monit Assess 2013;185:1265-72.
32 Shah ASV, Langrish JP, Nair H, McAllister DA, Hunter AL, Donaldson K, et al. Global association of air pollution and heart failure: A systematic review and meta-analysis. Lancet;382:1039-48.

33 Evans GW, Colome SD, Shearer DF. Psychological reactions to air pollution. Environ Res 1988;45:1-15.

$34 \mathrm{Lim}$ YH, Kim H, Kim JH, Bae S, Park HY, Hong YC. Air pollution and symptoms of depression in elderly adults. Environ Health Perspect 2012;120:1023-8

35 Jacobs SV, Evans GW, Catalano R, Dooley D. Air pollution and depressive symptomatology: Exploratory analyses of intervening psychosocial factors. Popul Environ 1984;7:260-72.

36 Briere J, Downes A, Spensley J. Summer in the city: Urban weather conditions and psychiatric emergency-room visits. J Abnorm Psychol 1983;92:77-80.

37 Rotton J, Frey J. Psychological costs of air pollution: Atmospheric conditions, seasonal trends, and psychiatric emergencies. Popul Environ 1984:7:3-16.

38 Strahilevitz M, Strahilevitz A, Miller JE. Air pollutants and the admission rate of psychiatric patients. Am J Psychiatry 1979;136:205-7.

39 Szyszkowicz M, Willey JB, Grafstein E, Rowe BH, Colman I. Air pollution and emergency department visits for suicide attempts in Vancouver, Canada. Environ Health Insights 2010;4:79-86.

40 Szyszkowicz M, Rowe BH, Colman I. Air pollution and daily emergency department visits for depression. Int I Occup Med Environ Health 2009;22:355-62.

41 Szyszkowicz M. Air pollution and emergency department visits for depression in Edmonton, Canada. Int J Occup Med Environ Health 2007;20:241-5.

42 Kim C, Jung SH, Kang DR, Kim HC, Moon KT, Hur NW, et al. Ambient particulate matter as a risk factor for suicide. Am J Psychiatry 2010;167:1100-7.

43 Biermann T, Stilianakis N, Bleich S, Thürauf N, Kornhuber J, Reulbach U. The hypothesis of an impact of ozone on the occurrence of completed and attempted suicides. Med Hypotheses 2009;72:338-41.

44 Bowler RM, Harris M, Gocheva V, Wilson K, Kim Y, Davis SI, et al. Anxiety affecting parkinsonian outcome and motor efficiency in adults of an Ohio community with environmental airborne manganese exposure. Int I Hyg Environ Health 2012;215:393-405.

45 Colditz GA, Manson JE, Hankinson SE. The Nurses' Health Study: 20-year contribution to the understanding of health among women. J Womens Health 1997;6:49-62.

46 Ranft U, Schikowski T, Sugiri D, Krutmann J, Kramer U. Long-term exposure to traffic-related particulate matter impairs cognitive function in the elderly. Environ Res 2009;109:1004-11.

47 Zhu Y, Hinds WC, Kim S, Sioutas C. Concentration and size distribution of ultrafine particles near a major highway. J Air Waste Manag Assoc 2002;52:1032-42.

48 Sioutas C, Delfino RJ, Singh M. Exposure assessment for atmospheric ultrafine particles (UFPS) and implications in epidemiologic research. Environ Health Perspect 2005;113:947-55.

49 Karner AA, Eisinger DS, Niemeier DA. Near-roadway air quality: Synthesizing the findings from real-world data. Environ Sci Technol 2010;44:5334-44.

50 Yanosky JD, Paciorek Cl, Suh $\mathrm{HH}$. Predicting chronic fine and coarse particulate exposures using spatiotemporal models for the northeastern and midwestern United States. Environ Health Perspect 2009;117:522-9.

51 Yanosky JD, Paciorek Cl, Schwartz J, Laden F, Puett R, Suh HH. Spatio-temporal modeling of chronic PM10 exposure for the Nurses' Health Study. Atmos Environ 2008;42:4047-62.

52 Yanosky J, Paciorek C, Laden F, Hart J, Puett R, Liao D, et al. Spatio-temporal modeling of particulate air pollution in the conterminous united states using geographic and meteorological predictors. Environ Health 2014;13:63.

53 Crown S, Crisp AH. A short clinical diagnostic self-rating scale for psychoneurotic patients. BrJ Psychiatry 1966;112:917-23.

54 Mavissakalian M, Michelson L. The Middlesex Hospital Questionnaire A validity study with american psychiatric patients. BrJ Psychiatry 1981;139:336-40.

55 Albert CM, Chae CU, Rexrode KM, Manson JE, Kawachi I. Phobic anxiety and risk of coronary heart disease and sudden cardiac death among women. Circulation 2005:111:480-7.

56 Haines AP, Imeson JD, Meade TW. Phobic anxiety and ischaemic heart disease. Br Med J (Clin Res Ed) 1987;295:297-9.

57 Kawachi I, Sparrow D, Vokonas PS, Weiss ST. Decreased heart rate variability in men with phobic anxiety (data from the Normative Aging Study). Am J Cardiol 1995; 75:882-5.

58 Okereke OI, Prescott J, Wong JY, Han J, Rexrode KM, De Vivo I. High phobic anxiety is related to lower leukocyte telomere length in women. PLoS One 2012;7:e40516.

59 Watkins LL, Blumenthal JA, Babyak MA, Davidson JR, McCants CB, Jr., O'Connor C, et al. Phobic anxiety and increased risk of mortality in coronary heart disease. Psychosom Med 2010;72:664-71.

60 Weisskopf MG, Chen H, Schwarzschild MA, Kawachi I, Ascherio A. Prospective study of phobic anxiety and risk of parkinson's disease. Mov Disord 2003:18:646-51. 
61 McGrath M, Kawachi I, Ascherio A, Colditz GA, Hunter DJ, De Vivo I. Association between catechol-o-methyltransferase and phobic anxiety. Am / Psychiatry 2004:161:1703-5.

62 Berkman LF, Syme SL. Social networks, host resistance, and mortality: A nine-year follow-up study of Alameda County residents. Am J Epidemiol 1979;109:186-204.

63 Ware JE, Jr., Sherbourne CD. The MOS 36-item short-form health survey (SF-36). I. Conceptual framework and item selection. Med Care 1992;30:473-83.

64 United States Department of Agriculture. Documentation: 2010 rural-urban commuting area (RUCA) codes. June 2, 2014. http://www. ers.usda.gov/data-products/rural-urban-commuting-area-codes/ documentation.aspx.

65 Kawachi I, Colditz GA, Ascherio A, Rimm EB, Giovannucci E, Stampfer MJ. et al. Prospective study of phobic anxiety and risk of coronary heart disease in men. Circulation 1994;89:1992-7.

66 Bell ML, Kim JY, Dominici F. Potential confounding of particulate matter on the short-term association between ozone and mortality in multisite time-series studies. Environ Health Perspect 2007;115:1591-5.

67 Brunekreef B, Holgate ST. Air pollution and health. Lance 2002;360:1233-42.

68 Babisch W, Wolf K, Petz M, Heinrich J, Cyrys J, Peters A. Associations between traffic noise, particulate air pollution, hypertension, and isolated systolic hypertension in adults: The KORA Study. Environ Health Perspect 2014;122:492-8.

69 Kioumourtzoglou MA, Spiegelman D, Szpiro AA, Sheppard L, Kaufman ID, Yanosky JD, et al. Exposure measurement error in PM2.5 health effects studies: A pooled analysis of eight personal exposure validation studies. Environ Health 2014;13:2.

70 Buchner DM, Wagner EH. Preventing frail health. Clin Geriatr Med 1992;8:1-17.

$71 \mathrm{Ng} \mathrm{F}$, Berk M, Dean O, Bush Al. Oxidative stress in psychiatric disorders: Evidence base and therapeutic implications. Int Neuropsychopharmacol 2008;11:851-76.

72 de Oliveira MR, Silvestrin RB, Mello e Souza T, Moreira JCF. Oxidative stress in the hippocampus, anxiety-like behavior and decreased locomotory and exploratory activity of adult rats: Effects of sub acute vitamin A supplementation at therapeutic doses. Neurotoxicology 2007;28:1191-9.

73 Salim S, Sarraj N, Taneja M, Saha K, Tejada-Simon MV, Chugh G. Moderate treadmill exercise prevents oxidative stress-induced anxiety-like behavior in rats. Behav Brain Res 2010;208:545-52

74 Salim S, Asghar M, Chugh G, Taneja M, Xia Z, Saha K. Oxidative stress: A potential recipe for anxiety, hypertension and insulin resistance. Brain Res 2010;1359:178-85.

75 Patki G, Solanki N, Atrooz F, Allam F, Salim S. Depression, anxiety-like behavior and memory impairment are associated with increased oxidative stress and inflammation in a rat model of social stress. Brain Res 2013;1539:73-86

76 Engler H, Doenlen R, Engler A, Riether C, Prager G, Niemi M-B, et al. Acute amygdaloid response to systemic inflammation. Brain Behav Immun 2011;25:1384-92.

77 Pitsavos C, Panagiotakos DB, Papageorgiou C, Tsetsekou E, Soldatos C, Stefanadis C. Anxiety in relation to inflammation and coagulation markers, among healthy adults: The Attica Study. Atherosclerosis 2006;185:320-6.
78 Liukkonen T, Räsänen P, Jokelainen J, Leinonen M, Järvelin MR, Meyer-Rochow VB, et al. The association between anxiety and c-reactive protein (CRP) levels: Results from the Northern Finland 1966 Birth Cohort Study. Eur Psychiatry 2011;26:363-9.

79 Vogelzangs N, Beekman ATF, de Jonge P, Penninx BWJH. Anxiety disorders and inflammation in a large adult cohort. Transl Psychiatry 2013:3.e249.

80 Bankier B, Barajas J, Martinez-Rumayor A, Januzzi JL. Association between c-reactive protein and generalized anxiety disorder in stable coronary heart disease patients. Eur Heart / 2008;29:2212-7.

81 Campbell A, Oldham M, Becaria A, Bondy SC, Meacher D, Sioutas C et al. Particulate matter in polluted air may increase biomarkers of inflammation in mouse brain. Neurotoxicology 2005;26:133-40.

82 Calderon-Garciduenas L, Maronpot RR, Torres-Jardon R, HenriquezRoldan C, Schoonhoven R, Acuna-Ayala H, et al. DNA damage in nasa and brain tissues of canines exposed to air pollutants is associated with evidence of chronic brain inflammation and neurodegeneration. Toxicol Pathol 2003;31:524-38.

83 MohanKumar SM, Campbell A, Block M, Veronesi B. Particulate matter, oxidative stress and neurotoxicity. Neurotoxicology 2008:29:479-88

84 Mikkelsen RL, Middelboe T, Pisinger C, Stage KB. Anxiety and depression in patients with chronic obstructive pulmonary disease (COPD). A review. Nord I Psychiatry 2004;58:65-70.

85 Livermore N, Sharpe L, McKenzie D. Panic attacks and panic disorder in chronic obstructive pulmonary disease: A cognitive behavioral perspective. Respir Med 2010;104:1246-53.

86 Griez E, Schruers K. Experimental pathophysiology of panic. J Psychosom Res 1998;45:493-503.

87 Gehi AK, Sears S, Goli N, Walker TJ, Chung E, Schwartz J, et al. Psychopathology and symptoms of atrial fibrillation: Implications for therapy. J Cardiovasc Electrophysiol 2012;23:473-8.

88 Katon W, Lin EHB, Kroenke K. The association of depression and anxiety with medical symptom burden in patients with chronic medical illness. Gen Hosp Psychiatry 2007;29:147-55.

89 Roy-Byrne PP, Davidson KW, Kessler RC, Asmundson GJG, Goodwin RD, Kubzansky L, et al. Anxiety disorders and comorbid medical illness. Gen Hosp Psychiatry 2008;30:208-25.

90 Araujo JA, Nel AE. Particulate matter and atherosclerosis: Role of particle size, composition and oxidative stress. Part Fibre Toxicol 2009;6:24

91 Diociaiuti M, Balduzzi M, De Berardis B, Cattani G, Stacchini G, Ziemacki G, et al. The two PM2.5 (fine) and PM2.5-10 (coarse) fractions: Evidence of different biological activity. Environ Res 2001:86:254-62

92 Kelly FJ. Oxidative stress: Its role in air pollution and adverse health effects. Occup Environ Med 2003;60:612-6.

93 Li N, Sioutas C, Cho A, Schmitz D, Misra C, Sempf J, et al. Ultrafine particulate pollutants induce oxidative stress and mitochondrial damage. Environ Health Perspect 2003;111:455-60.

94 Pakkanen TA, Loukkola K, Korhonen CH, Aurela M, Mäkelä T, Hillamo RE, et al. Sources and chemical composition of atmospheric fine and coarse particles in the Helsinki area. Atmos Environ 2001;35:5381-91.

(c) BMJ Publishing Group Ltd 2015 